\title{
A COMPUTER-BASED DATABASE FOR RADIOCARBON DATES OF CENTRAL ANDEAN ARCHAEOLOGY
}

\author{
ADAM MICHCZYŃSKI, ${ }^{1}$ ANDRZEJ KRZANOWSKI, ${ }^{2}$ MIECZYSEAW F. PAZDUR ${ }^{1,3}$ and \\ MARIUSZ S. ZIOEKOWSKI ${ }^{4}$
}

\begin{abstract}
We established a database of ${ }^{14} \mathrm{C}$ dates from archaeological sites of the Central Andes region of Peru, Ecuador and Bolivia on an IBM PC-compatible microcomputer running on an MS-DOS operating system using software package dBASE IV, version 1.1. Relevant data are stored in three DBF-type database files. The file ANDY.DBF contains information on dates and samples; REFERENC.DBF contains references to relevant publications and CALAND.DBF contains calibrated dates. The total number of records of the ANDY database slightly exceeds 2650.
\end{abstract}

\section{INTRODUCTION}

The need for computer-based database systems for management and storage of radiocarbon dates and associated information was recognized in the 1980s, especially at Groningen in 1981 (Otlet and Walker 1983) and in 1987 (Kra 1990; Walker et al.1990), Seattle in 1982 (Gulliksen 1983; Moffett and Webb 1983), Trondheim in 1985 (Wilcock et al. 1985; Engelsman, Taayke and Mook 1986; Kra 1986) and beyond (Kra 1988, 1989). Several laboratories also established regional databases (Obelić 1989; Omoto 1989; van der Plicht 1992). Michczyński and Pazdur (1994) are in the process of implementing a similar database at the Gliwice Radiocarbon Laboratory. In 1989, a research project was initiated by the Andean Archaeological Mission of Warsaw University and the Gliwice Radiocarbon Laboratory, the main aim being to establish a database containing all available archaeological ${ }^{14} \mathrm{C}$ data from the central Andes-Peru, Bolivia and Ecuador.

\section{ThE DATABASE STRUCTURE}

The database was created on an IBM PC-compatible microcomputer running under an MS-DOS operating system using dBASE IV, version 1.1. All available relevant data are stored in three database files (DBF): 1) ANDY.DBF-contains information on dates and samples; 2) REFERENC.DBF-contains references to relevant publications; 3) CALAND.DBF-contains calibration data. An additional file, ANDY.DBT, contains relevant comments. The structure of the database represents a compromise solution to many problems we encountered during this study. After a preliminary analysis of selected papers published in archaeological journals, books and reports and in $R A D I O C A R B O N$, we realized that ${ }^{14} \mathrm{C}$ dates produced by laboratories all over the world during the last 40 years are reported in many different styles. Some dates appear in publications with comprehensive archaeological and geological information and discussion of their cultural association, but many dates are published as merely numerical information in tables or footnotes. Further, dates are sometimes quoted without laboratory codes and dating uncertainties, and a common practice, especially in older papers, is to quote the dates as calibrated without indicating the method of calibration and curve used. Thus, after much consideration, we decided on a structure to meet both the requirements of the research project and the availability of the information and its significance.

\footnotetext{
${ }^{1}$ Department of Radioisotopes, Silesian Technical University, Krzywoustego 2, PL-44-100 Gliwice, Poland

${ }^{2}$ Institute of Geography, Jagellonian University, Grodzka 64, PL-31-018 Krakow, Poland

${ }^{3}$ Deceased 11 May 1995

${ }^{4}$ Andean Archaeological Mission, Institute of Archaeology, Warsaw University, Krakowskie Przedmiescie 34

PL-00-975 Warsaw
} 
The fundamental information on the sample and dating result is compiled in 49 fields of a single record of the ANDY database. Table 1 shows the structure of the record, including the fields, their types and size. The first two fields, LABCO and LABNO, represent the laboratory code and number, e.g., Gd-4791. Dates without codes and numbers are stored with an arbitrary code $Z Z Z Z$ and number for identification only. Fields 3-5, SITENAME, SITENO and SAMPLE, refer to the name and the number of the site from which the sample was collected, and the name attributed to the sample by the collector/submitter. Fields $6-9$ comprise the ages of the samples in conventional ${ }^{14} \mathrm{C}$ years $\mathrm{BP}$ (AGEBP) and the dating uncertainty (ERMAX, ERMIN). DT gives information about the date. Categories include: date with symmetrical uncertainty, date with asymmetrical uncertainty, date quoted as younger than, date quoted as older than, date quoted as modern. We converted all dates quoted in $\mathrm{AD}$ or $\mathrm{BC}$ years to year $\mathrm{BP}$, noting this in the comments. This conversion was necessary for calibrating dates. Field DC13 contains the $\delta^{13} \mathrm{C}$ of the sample, either estimated or measured. MATERIAL and MATEXT indicate the type of organic material. MATERIAL is a keyword field, which is used to find dates of a certain nature, in this case, from the same sample material. The keywords for MATERIAL are: CHARCOAL, WOOD, PEAT, SOIL, HUMUS, PLANT FRAGMENTS, DETRITUS, GYTTJA, GRAIN, SHELL, SPELEOTHEM, CARBONATE, TEXTILE, BONE and OTHER. The supplementary field MATEXT contains more detailed information on the dated material. When even more specific identification (botanical, lithological or other) is available, it is entered in Field 13-IDAS. Field 14-IDBY contains the name of the person who made the identification. Fields 15-17 contain some technical information on the FRACTION, the preliminary chemical or physical TREATMENT and available information on possible contamination of the sample. Unfortunately, only a few dates are recorded with this technical information.

A concise description of the archaeological context of a sample, including the position of a sample within a site and its cultural association, is stored in the field CONTEXT. This is the most important field of the database. If relevant information about the cultural and chronological significance of the sample cannot fit into this field because of limited field size (128 characters), the excess data can be moved into the unlimited memo-type field ARCCOMMENT (39). PROVENIEN (19) is the second keyword field; it is distinguishable from CONTEXT in that it identifies the exact location from which the sample was taken and may contain the keywords EXCAVATION, EXPOSURE, TRENCH, CORE, FINDING, MUSEUM and OTHER. SITEDESC describes the site itself, whereas the ENVIRON describes the environment and notes the geology, geomorphology and topography of the surroundings. Fields 22-25 contain data on general cultural periods-the general cultural period (PER) and phase (PHASE), and the regional or local period and phase (REGPERIOD and REGPHASE), followed by COMMENT on these periods.

The next group of fields (27-33) contains data on the political boundaries and geographical location of the site:

C - first letter of the name of the country

AU1-code of first-order administrative unit in the country

ADMUNIT2, ADMUNIT3-2nd- and 3rd-order units

LAT-latitude

LONG-longitude

ALT-elevation in meters above sea level.

COLLDATE and COLLBY are the collection date (year only) and the name of the collector. PROJECT contains a short name or acronym of the research project. LABDATE gives the year when the sample was dated. Comments of a technical, methodological or interpretational nature that 
TABLE 1. Structure of ANDY Database Record

\begin{tabular}{|c|c|c|c|}
\hline Field & Field name & Type & Width \\
\hline 1 & LABCO & Character & 4 \\
\hline 2 & LABNO & Character & 7 \\
\hline 3 & STENAME & Character & 30 \\
\hline 4 & SITENO & Character & 30 \\
\hline 5 & SAMPLE & Character & 20 \\
\hline 6 & DT & Numeric & 2 \\
\hline 7 & AGEBP & Numeric & 5 \\
\hline 8 & ERMAX & Numeric & 4 \\
\hline 9 & ERMIN & Numeric & 4 \\
\hline 10 & $\mathrm{DC} 13$ & Numeric & 6 \\
\hline 11 & MATERIAL & Character & 15 \\
\hline 12 & MATEXT & Character & 25 \\
\hline 13 & IDAS & Character & 80 \\
\hline 14 & IDBY & Character & 50 \\
\hline 15 & FRACTION & Character & 25 \\
\hline 16 & TREATMENT & Character & 50 \\
\hline 17 & CONTAM & Character & 50 \\
\hline 18 & CONTEXT & Character & 128 \\
\hline 19 & PROVENIEN & Character & 25 \\
\hline 20 & SITEDESC & Character & 220 \\
\hline 21 & ENVIRON & Character & 160 \\
\hline 22 & PER & Character & 11 \\
\hline 23 & PHASE & Character & 25 \\
\hline 24 & REGPERIOD & Character & 25 \\
\hline 25 & REGPHASE & Character & 25 \\
\hline 26 & COMMENT & Character & 30 \\
\hline 27 & $\mathrm{C}$ & Character & 1 \\
\hline 28 & AU1 & Character & 2 \\
\hline 29 & ADMUNIT2 & Character & 30 \\
\hline 30 & ADMUNIT3 & Character & 30 \\
\hline 31 & LAT & Character & 6 \\
\hline 32 & LONG & Character & 6 \\
\hline 33 & ALT & Numeric & 4 \\
\hline 34 & COLLDATE & Numeric & 4 \\
\hline 35 & COLLBY & Character & 25 \\
\hline 36 & PROJECT & Character & 25 \\
\hline 37 & LABDATE & Numeric & 4 \\
\hline 38 & LABCOMMENT & Memo & 10 \\
\hline 39 & ARCCOMMENT & Memo & 10 \\
\hline 40 & REF1 & Character & 8 \\
\hline 41 & PAGE1 & Character & 10 \\
\hline 42 & REF2 & Character & 8 \\
\hline 43 & PAGE2 & Character & 10 \\
\hline 44 & REF3 & Character & 8 \\
\hline 45 & PAGE3 & Character & 10 \\
\hline 46 & REF4 & Character & 8 \\
\hline 47 & PAGE4 & Character & 10 \\
\hline 48 & REF5 & Character & 8 \\
\hline 49 & PAGE5 & Character & 10 \\
\hline
\end{tabular}


can be useful in further analysis are entered into LABCOMMENT. ARCCOMMENT is used to store supplementary archaeological or geological information, including discussions of chronological significance, stratigraphic sequence and other relevant dates for the same sample, site or culture. Fields 40-49, REF1-REF5 and PAGE1-PAGE5 contain the special codes used to identify references stored in the separate, relational database file REFERENCE.DBF.

\section{THE SOFTWARE PROGRAM}

Our dBASE IV v.1.1 program includes options for displaying, printing and saving information in form of a report similar to the format used in RADIOCARBON. We can also sort the records in many different ways. Figure 1 shows an example of the screen display of a basic report.

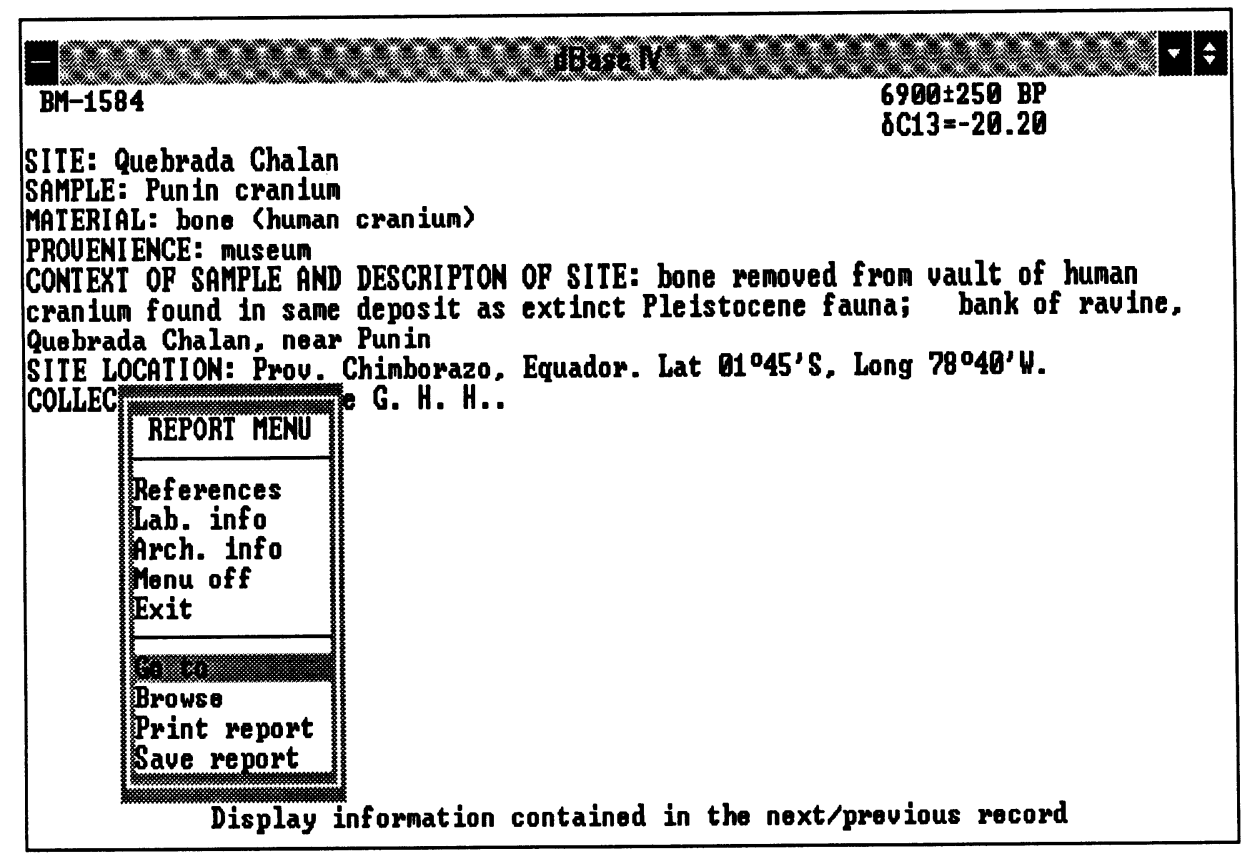

Fig. 1. An example of a screen display of a basic report

Additional information about the date is available under REPORT MENU, with the following options:

REFERENCES displays bibliographic references to the date of interest. Figure 2 shows an example of this window.

LAB.INFO displays specific laboratory information for each date, e.g., dated fraction, chemical pretreatment or other laboratory comment.

ARCH.INFO displays archaeological information about the date (e.g., period, phase). If the date contains archaeological comment, then $M E M O$ appears at the end of the display. After pressing CtrlHome, the archaeological comment is shown on the screen (Fig. 3).

MENU OFF removes REPORT MENU from the screen. This option is useful if the menu covers part of the displayed information. The menu may be restored by pressing F2. 


\begin{tabular}{|c|}
\hline $\begin{array}{ll}\text { BH-1584 } & 6900 \pm 250 \text { BP } \\
\text { SITE: Quebrada Chalan } & 8 C 13=-20.20 \\
\end{array}$ \\
\hline 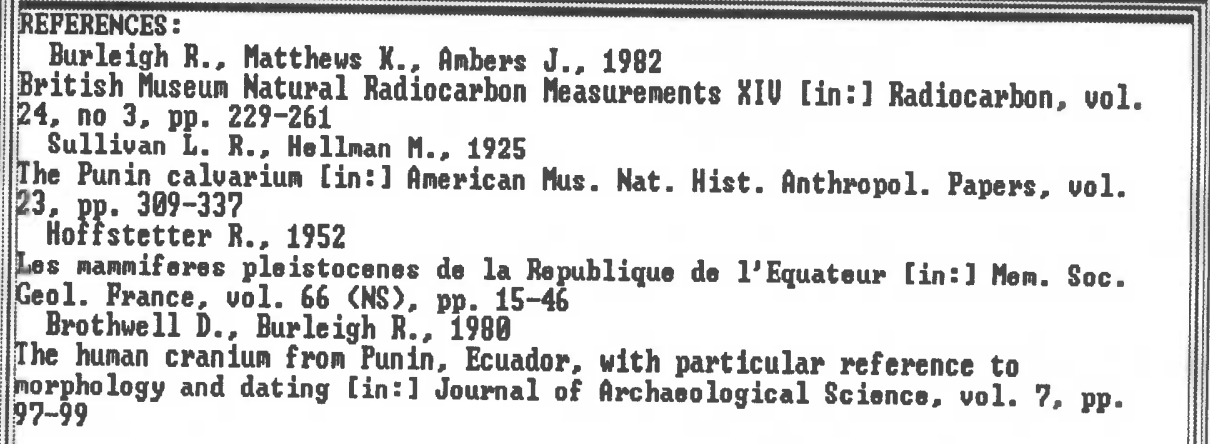 \\
\hline
\end{tabular}

Fig. 2. An example of the REFERENCES window

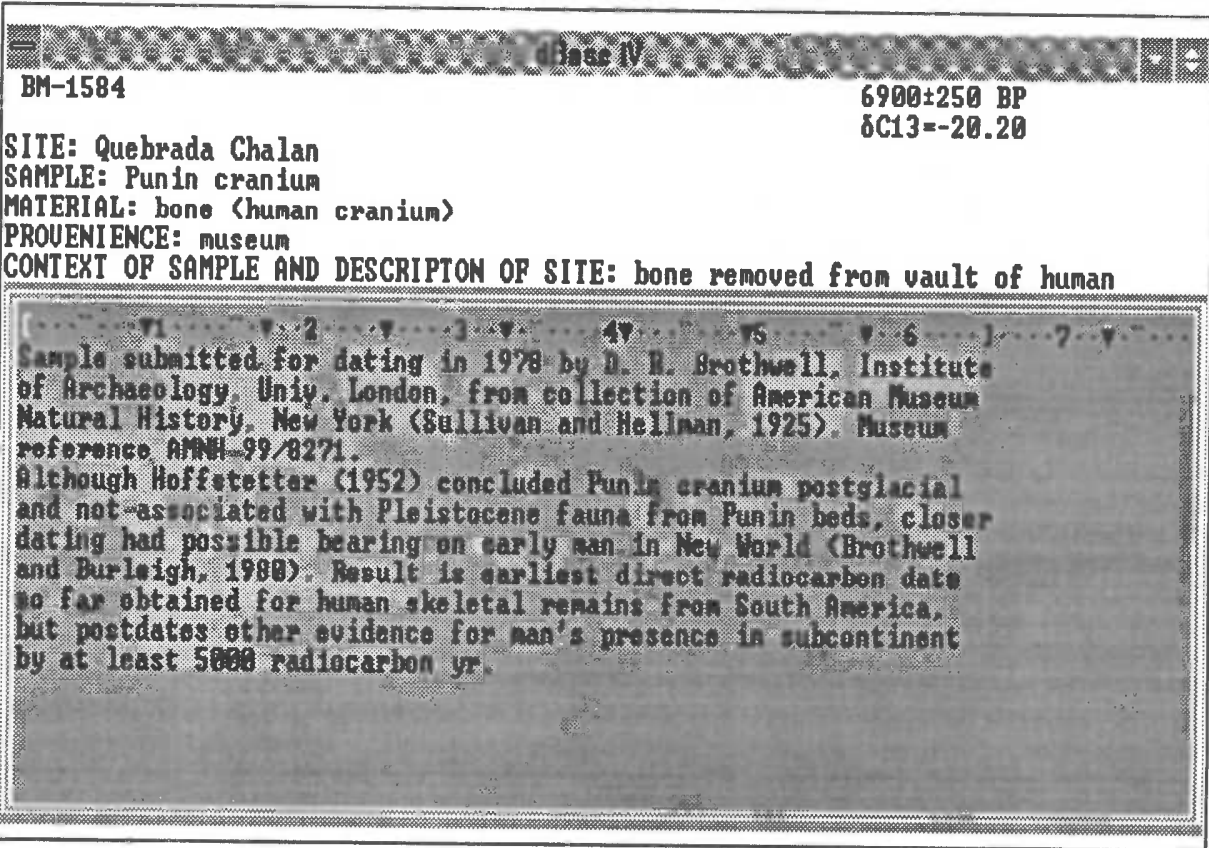

Fig. 3. An example of the archaeological comment in a memo-type field available through the ARCH.INFO window 
EXIT ends the execution of the program (return to dBase IV prompt).

GO TO displays basic information about the next or previous record in the ANDY.DBF file.

BROWSE allows one to view the database in table format. All suboptions of BROWSE are active in this mode (e.g., change of record sequence). After pressing (ESC or Ctrl-END) from this option a basic report for the last marked date will be displayed on the screen.

PRINT REPORT prints complete information about the date (basic, laboratory, archaeological and bibliographic).

SAVE REPORT saves complete information (as above) on a chosen date or a specified number of dates to a selected file. Before saving the information, a file name must be specified.

\section{THE CALIBRATION PROGRAM}

The main aim of our project was to gather selected information for future archaeological and chronological studies. Thus, we had to consider different calibration programs, which is not a simple and straightforward task. We searched for the best method of presenting calibration results in simple numerical form (Krzanowski et al. 1994) and decided on intervals that show the calendric age with probabilities $68.3 \%$ and $95.4 \%$, which correspond with 1 and $2 \sigma$, respectively. Stuiver and Reimer (1993) in CALIB 3.0 and van der Plicht (1993) in the Groningen Calibration Program use the same methods.

We calibrated the ${ }^{14} \mathrm{C}$ dates of the ANDY database using the Gliwice Calibration Program (Pazdur and Michczyńska 1989) ver. 5.2. The calibration curves used in the calculation were taken from Calibration 1993 (Stuiver, Long and Kra 1993) and are practically the same as the curves used in CALIB 3.0. The only difference is that we decided to terminate the calibration curve at $9439 \mathrm{BC}$ at the end of the German oak and pine calibration. We did not correct to $c a .40 \mathrm{yr}$ for systematic age differences between northern and southern hemispheres, according to Vogel et al. (1993), because we believe that this correction, obtained for wood samples from South Africa (latitude $25^{\circ} \mathrm{S}-35^{\circ} \mathrm{S}$ ) may not be valid for the strictly equatorial region of the Andes.

\section{RESULTS}

The total number of records in the ANDY database slightly exceeds 2650. Information gathered on dates in database has been published in catalogue form (Ziókowski et al. 1994). Three introductory chapters describe the archaeological background (Ziółkowski 1994), technical aspects of the database structure (Michczyński 1994) and a general introduction to ${ }^{14} \mathrm{C}$ dating (Pazdur and Pazdur 1994).

\section{ACKNOWLEDGMENTS}

This study was supported by the State Committee for Scientific Research through Grant PB 0857/ $\mathrm{P} 1 / 93$. The authors are highly indebted to numerous colleagues from ${ }^{14} \mathrm{C}$ laboratories who helped us by submitting data from their laboratory records.

\section{REFERENCES}

Engelsman, F. M. R., Taayke, E. and Mook, W. G. 1986 Groningen ${ }^{14} \mathrm{C}$ data base. In Stuiver, M. and Kra, R. S., eds., Proceedings of the 12 th International ${ }^{14} \mathrm{C}$ Conference. Radiocarbon 28(2A): 788-796.

Gulliksen, S. 1983 Radiocarbon database: A pilot project. In Stuiver, M. and Kra, R. S., eds., Proceedings of the 11 th International ${ }^{14} \mathrm{C}$ Conference. Radiocarbon $25(2)$ : 661-666. 
Kra, R. S. 1986 Report of the ${ }^{14} \mathrm{C}$ Data Base Workshop. In Stuiver, M. and Kra, R. S., eds., Proceedings of the 12th International ${ }^{14} \mathrm{C}$ Conference. Radiocarbon $28(2 \mathrm{~A})$ : $800-802$.

1988 Updating the past: The establishment of the International Radiocarbon Data Base. American Antiquity 53(1): 118-125.

1989 The International Radiocarbon Data Base: A progress report. In Long, A., Kra, R. S. and Srdo丈, D., eds., Proceedings of the 13 th International ${ }^{14} \mathrm{C}$ Conference. Radiocarbon 31(3): 1067-1076.

1990 Establishing the International Radiocarbon Data Base. In Mook, W. G. and Waterbolk, H. T., eds., Proceedings of the Second International Symposium, ${ }^{14} \mathrm{C}$ and Archaeology. PACT 29: 13-20.

Krzanowski, A., Michczyński, A., Pazdur, M. F. and Ziółkowski, M. S. 1994 Computer databank of radiocarbon dates of archaeological cultures of Central Andes. Zeszyty Naukowe Politechniki Slaskiej, Geo chronometria 10: 139-151 (in Polish).

Michczyński, A. 1994 Databank for radiocarbon dates of archaeological cultures of Peru, Ecuador and Bolivia-technical aspects. In Ziołkowski, M. S., Pazdur, M. F., Krzanowski, A. and Michczynski, A., eds., Andes. Radiocarbon Database for Bolivia, Ecuador and Peru. Andean Archaeological Mission of the Institute of Archaeology, Warsaw University \& Gliwice Radiocarbon Laboratory of the Institute of Physics, Silesian Technical University, Warsaw-Gliwice.

Michczyński, A. and Pazdur, M. F. 1994 Gliwice radiocarbon data bank-present status. Zeszyty Naukowe Politechniki Slaskiej, Geochronometria 10: 47-59 (in Polish).

Moffett, J. C. and Webb, R. E. 1983 Database management systems, radiocarbon and archaeology. In Stuiver, M. and Kra, R. S., eds., Proceedings of the 11th International ${ }^{14} \mathrm{C}$ Conference. Radiocarbon 25(2): 667668.

Obelic, B. 1989 The radiocarbon data base at Rudjer Boškovi Institute Radiocarbon Laboratory. In Long, A., Kra, R. S. and Srdox, D., eds., Proceedings of the 13th International ${ }^{14} \mathrm{C}$ Conference. Radiocarbon 31(3): 1057-1062.

Omoto, K. 1989 The radiocarbon data base of Japan. In Long, A., Kra, R. S. and Srdox, D., eds., Proceedings of the 13th International ${ }^{14} \mathrm{C}$ Conference. Radiocarbon 31(3): 1063-1066.

Otlet, R. L. and Walker, A. J. 1983 The computer writing of radiocarbon reports and further developments in the storage and retrieval of archaeological data. In Mook, W. G. and Waterbolk, H. T., eds., Proceedings of the 1st International Symposium ${ }^{14} \mathrm{C}$ and Archaeology. PACT 8: 91-106.

Pazdur, A. and Pazdur, M. F. 1994 Fundamental concepts of archaeological applications of the radiocarbon dating method. In Ziołkowski, M. S., Pazdur, M. F., Krza- nowski, A. and Michczyński, A., eds., Andes. Radiocarbon Database for Bolivia, Ecuador and Peru. Andean Archaeological Mission of the Institute of Archaeology, Warsaw University \& Gliwice Radiocarbon Laboratory of the Institute of Physics, Silesian Technical University, Warsaw-Gliwice.

Pazdur, M. F. and Michczyńska, D. J. 1989 Improvement of the procedure for probabilistic calibration of radiocarbon dates. In Long, A., Kra, R. S. and Srdoð, D., eds., Proceedings of the 13 th International ${ }^{14} \mathrm{C}$ Conference. Radiocarbon 31(3): 824-832.

Stuiver, M., Long, A. and Kra, R. S., eds. Calibration 1993. Radiocarbon 35(1): 1-244.

Stuiver, M. and Reimer, P. J. 1993 Extended ${ }^{14} \mathrm{C}$ data base and revised CALIB $3.0^{14} \mathrm{C}$ age calibration program. In Stuiver, M. Long, A. and Kra, R. S., eds. Calibration 1993. Radiocarbon 35(1): 215-231.

van der Plicht, J. 1992 The new Groningen ${ }^{14} \mathrm{C}$ data base. In Long, A. and Kra, R. S., eds., Proceedings of the 14th International ${ }^{14} \mathrm{C}$ Conference. Radiocarbon 34(3): 493-499.

1993 The Groningen radiocarbon calibration program. In Stuiver, M., Long, A. and Kra, R.S., eds. Calibration 1993. Radiocarbon 35(1): 231-239.

Vogel, J. C., Fuls, A. M., Visser, E. and Becker, B. 1993 Pretoria calibration curve for short-lived samples, 1930-3350 BC. In Stuiver, M., Long, A. and Kra, R. S. eds., Calibration 1993. Radiocarbon 35(1): 73-87.

Walker, A. J., Charlesworth, S. A., Otlet, R. L. and Lavell, C. 1990 Setting up the CBA Index of UK Radiocarbon Dates as a Microcomputer Data Base. In Mook, W. G. and Waterbolk, H. T., eds., Proceedings of the Second International Symposium, ${ }^{14} \mathrm{C}$ and $\mathrm{Ar}$ chaeology. PACT 29: 23-34.

Wilcock, J. D., Otlet, R. L., Walker, A. J., Charlesworth, S. A. and Drodge, J. 1986 Establishment of a working data base for the international exchange of ${ }^{14} \mathrm{C}$ data using universal transfer formats. In Stuiver, $\mathrm{M}$. and $\mathrm{Kra}$, R. S., eds., Proceedings of the 12 th International ${ }^{14} \mathrm{C}$ Conference. Radiocarbon 28(2A): 781-787.

Ziółkowski, M. S. 1994 Some problems of the radiocarbon dating of the Central Andean cultures. In Ziołkowski, M. S., Pazdur, M. F., Krzanowski, A. and Michczyński, A., eds., Andes. Radiocarbon Database for Bolivia, Ecuador and Peru. Andean Archaeological Mission of the Institute of Archaeology, Warsaw University \& Gliwice Radiocarbon Laboratory of the Institute of Physics, Silesian Technical University, Warsaw-Gliwice.

Zíłkowski, M. S., Pazdur, M. F., Krzanowski, A. and Michczyński, A., eds. 1994 Andes. Radiocarbon Database for Bolivia, Ecuador and Peru. Andean Archaeological Mission of the Institute of Archaeology, Warsaw University \& Gliwice Radiocarbon Laboratory of the Institute of Physics, Silesian Technical University, Warsaw-Gliwice: 1-604. 